\title{
Consumption habits of pregnant women in the Jazan region, Saudi Arabia: a descriptive study
}

\author{
Tariq Al Bahhawi ${ }^{1^{*}} \mathbb{E}$, Abrar Anwar Doweri², Rawan Mohammed Sawadi², Mariam Yahya Awaji², \\ Mada Mohammad Jarad ${ }^{2}$, Zahra Yahya Sulays ${ }^{2}$ and Khadijah Abdulrhman Madkor ${ }^{2}$
}

\begin{abstract}
Objective: Maternal nutritional habits are critical for the health of both mother and offspring. Postpartum outcomes for mother and infant are strongly influenced by the mother's nutritional status. Information about consumption habits among pregnant women in Saudi Arabia is scarce. Thus, this study aims to describe the consumption habits of pregnant women in the Jazan region, Saudi Arabia.

Results: Meat, fish, and fruits were consumed by $97 \%, 86 \%$, and $90 \%$ of the sample. Sugary desserts, fast food, and canned food were consumed by $90 \%, 81 \%$, and $71 \%$ of the sample. Caffeine, juices, and milk were consumed by $75 \%$, $92 \%$, and $81 \%$ of the sample. Previous percentages show general higher consumption habits of food and beverages. Over-the-counter medication was used by only $17 \%$. Folic acid, iron, and calcium use by $77 \%, 64 \%$, and $58 \%$ of the sample, respectively. These percentage shows conservative use of Over-the-counter medication and sub-optimal use of important dietary supplements. Moreover, there was a positive association between caffeine intake and trimesters. Furthermore, there was negative association between education level and fish intake. Finally, canned foods consumption was higher among low income pregnant women.
\end{abstract}

Keywords: Pregnancy, Diet, Beverages, Medication, Jazan

\section{Introduction}

Consumption habits during pregnancy are important from public health prospective for promotion of healthy pregnancy. These consumption habits can be either related to foods, beverages or medications. Good maternal nutrition status is crucial for women's health and the health, survival, and development of their infants $[1,2]$. The mother's consumption habits during pregnancy are an important determent of postpartum outcomes for both mother and child [3, 4].

Some food and beverages are rich sources of essential nutrients such as vegetables, fruits, meat, sea food and milk products [5]. On the other hands, some foods and beverages contain particular components or toxins

\footnotetext{
*Correspondence: albahhawi@gmail.com

${ }^{1}$ Department of Family and Community Medicine, Faculty of Medicine, Jazan University, Jazan, Kingdom of Saudi Arabia

Full list of author information is available at the end of the article
}

that can lead to serious consequences [6-8]. Moreover, pregnant women are advised to increase some nutrients, such as protein, carbohydrates, fat, and some vitamins and minerals in order to meet the progressive demands of physiological changes in maternal tissues and fetal growth $[2,6]$. Thus, the data about food groups and beverages consumption during pregnancy are important to evaluate the pattern of foods and beverages consumption habits and approximate the healthy diet habits.

Medications are one of the most common consumed substance during pregnancy. Multinational study in Europe reported that around $80 \%$ of pregnant women used at least one medication during pregnancy (prescribed or over-the counter OTC) [9]. In the USA, around $50 \%$ of the pregnant women report use over-the counter (OTC) medications (at least one medication during pregnancy) [10]. Although, no randomized controlled trials have been conducted to produced clear evidence 
or guidance on the use of OTC medications during pregnancy [11].

In Saudi Arabia, a national survey revealed that only a small percentage of the Saudi population met the dietary guidelines [12]. Moreover, a study conducted among pregnant women showed the same results [13]. However, around 40\% of pregnant women in Saudi Arabia use medication during pregnancy [14]. There is limited data, however, for consumption habits by pregnant women in Saudi Arabia, especially consumption of beverages and OTC medications. Therefore, this study aims to evaluate the consumption habits of pregnant women regarding food, beverages, and medications.

\section{Main text}

\section{Methods}

A cross-sectional study was conducted in the Jazan region in five primary health care $(\mathrm{PHC})$. centers in April and May 2017. Jazan is one of the smallest regions in Saudi Arabia. The region is situated in the southwest of the country and aligns with the southern seaboard of Yemen. According to the 2015 census conducted by the Saudi General Authority of Statistics, the total population of the region is about 1.5 million.

100 pregnant women were recruited from five PHC centers chosen randomly from all Jazan PHC centers. The original sample size was calculated to be 400 pregnant women, but due to the very low number of pregnant women attending prenatal care clinics, we ended up with 76 participants. After discussion with the ethical committee, we decided to extract phone numbers from the PHC files and contacted potential participants until we reached 100 .

The data were collected using a self-administered questionnaire comprising two parts. The first part contained questions about demographic information (such as age, education level, living standard, place of residence and gestational age). and the second part was the Food, Beverage, and Medication Intake Questionnaire (FBMIQ). which has been used previously [6]. The FBMIQ was originally designed to evaluate maternal consumption habits about certain foods, beverages and medications during pregnancy; it is not a comprehensive assessment of diet but rather a short survey about particular items consumed. It is assess how often and during which time are certain foods, beverages and medications consumed during the pregnancy period. On the other hand, it does not assess the portion size or number of servings. The FBMIQ was translated into Arabic and modified to fit cultural factors.

Data were entered, cleaned, and analyzed using SPSS version 20 (SPSS Inc, Chicago, IL, USA). Data analysis involved descriptive statistics and several inferential statistics techniques. The normality test for the study variables was assessed and all variables were normally distributed. The sociodemographic data were presented by frequency and percentage, except for age, which was shown by mean $(\mathrm{M})$ and standard deviation $(S D)$. Food, beverages, and medication data were presented by frequency and percentage. Pearson correlation coefficients between age and consumption habits were calculated. The Chi squared test and Fisher exact test were performed to determine the differences in consumption frequencies for meat, fish, fruit, canned food, desserts, fast food, milk, juice, caffeine, OTC and prescribed medication with grouping variables of level of education, income and trimesters. A p-value less than 0.05 was used as the cut-off level for statistical significance.

\section{Results}

The questionnaires were completed by 100 pregnant women. Their demographic characteristics are summarized as the following: The sample mean age was 27.8 years, with a SD of 5.9 years and a range of 16-42 years. Of the sample, $55 \%$ had received a university degree or higher. About $42 \%$ of the sample were pregnant women in their third trimester, $40 \%$ in their second trimester, and $18 \%$ in their first trimester. Around $52 \%$ of the sample have monthly income higher than 6000 Saudi Riyal (SR) and 48\% have 6000 SR or less.

Food consumption habits are presented in Table 1. The most commonly consumed category was any meat products (consumed by $97 \%$ of the pregnant women), followed by fruit and sugary desserts $(90 \%)$, then fish, fast food, and canned food ( $86 \%, 81 \%$, and $71 \%$, respectively).

Table 1 shows the beverage consumption habits of the sample, with $100 \%$ of the women drinking water and $92 \%$ of them drinking bottled water. Juices were consumed by $92 \%$ of the respondents. Milk was consumed by $81 \%$, followed by caffeinated beverages $(75 \%)$. Finally, energy drinks and non-alcoholic beer were the beverages least-often consumed by pregnant women ( $7 \%$ and $5 \%$, respectively).

Medication and vitamin consumption during pregnancy are shown in Table 1, which shows that prescribed medication was consumed by $95 \%$ of the respondents. Folic acid, iron, and calcium were the most-consumed medications, consumed by $77 \%, 64 \%$, and $58 \%$, respectively, of the respondents. OTC medications were consumed by $17 \%$ of the pregnant women.

Table 2 highlights the frequency of the consumption habits during pregnancy. Meat products were consumed 1-3 times per week for around 39\% of the respondents, while fish was consumed 1-3 times per week by $50 \%$. Fast food, fruits, sugary desserts, and canned food were consumed $1-3$ times per week by $31 \%$ to $44 \%$ during 
Table 1 Food, Beverage and medications consumption habits among pregnant women

\begin{tabular}{|c|c|}
\hline Substance consumed $\mathrm{n}=100$ & $\begin{array}{l}\text { Pregnant } \\
\text { women } \mathrm{N}(\%)\end{array}$ \\
\hline \multicolumn{2}{|l|}{ Food } \\
\hline Any meat & $97(97)$ \\
\hline Meat & $12(12.4)$ \\
\hline Chicken & $9(9.3)$ \\
\hline Both & $75(77.3)$ \\
\hline Other & $1(1.03)$ \\
\hline Any fish & $86(86)$ \\
\hline Tuna & $18(20.9)$ \\
\hline Greasy grouper & $27(31.4)$ \\
\hline Both & $40(46.5)$ \\
\hline Other fish & $1(1.2)$ \\
\hline Fresh fruit & $90(90)$ \\
\hline Bananas & $72(80)$ \\
\hline Oranges & $78(86.6)$ \\
\hline Apples & $74(82.2)$ \\
\hline Other fresh fruit & $23(25.5)$ \\
\hline Any canned foods & $71(71)$ \\
\hline Canned fruits/veggies & $37(52.1)$ \\
\hline Canned soup & $34(47.9)$ \\
\hline Canned tuna & $45(63.4)$ \\
\hline Other canned foods & $2(2.8)$ \\
\hline Sugary desserts & $90(90)$ \\
\hline Ice cream & $68(75.5)$ \\
\hline Baked desserts & $65(72.2)$ \\
\hline Chocolate & $78(86.6)$ \\
\hline Other desserts & $2(2.2)$ \\
\hline Fast foods & $81(81)$ \\
\hline Burgers & $58(71.6)$ \\
\hline French fries & $71(87.6)$ \\
\hline Chicken products & $41(50.6)$ \\
\hline Other fast foods & $3(3.7)$ \\
\hline \multicolumn{2}{|l|}{ Beverage } \\
\hline Any water & $100(100)$ \\
\hline Tap water & $10(10)$ \\
\hline Bottled water & $92(92)$ \\
\hline Home-filtered water & $5(5)$ \\
\hline Other water & $0(0)$ \\
\hline Any milk & $81(81)$ \\
\hline Organic & $1(1.2)$ \\
\hline Full fat & $60(74)$ \\
\hline Low fat & $19(23.5)$ \\
\hline Fat-free & $5(6.2)$ \\
\hline Any juice & $92(92)$ \\
\hline Orange juice & $75(81.5)$ \\
\hline Apple juice & $46(50)$ \\
\hline Mixed juice & $56(60.8)$ \\
\hline Other juice & $14(15.2)$ \\
\hline Caffeine & 75 (75) \\
\hline
\end{tabular}

Table 1 (continued)

\begin{tabular}{lc}
\hline Substance consumed $\mathbf{n}=\mathbf{1 0 0}$ & $\begin{array}{c}\text { Pregnant } \\
\text { women } \mathbf{N}(\%)\end{array}$ \\
\hline Coffee & $51(68)$ \\
Tea & $56(74.6)$ \\
Caffeinated drinks & $45(60)$ \\
Energy drinks & $7(7)$ \\
Red Bull & $0(0)$ \\
Code Red & $4(57.1)$ \\
Power Horse & $1(14.3)$ \\
Other & $3(42.8)$ \\
Non-alcoholic beer & $5(5)$ \\
Medication & \\
Over-the-counter & $17(17)$ \\
Medication & $2(11.7)$ \\
Decongestants & $3(17.6)$ \\
Cough/cold medications & $0(0)$ \\
Ibuprofen & $1(5.9)$ \\
Aspirin & $14(82)$ \\
Acetaminophen & $4(23.5)$ \\
Prescribed medication & $95(95)$ \\
Vitamins & $46(48.4)$ \\
Calcium & $58(61.05)$ \\
Morning sickness & $27(28.4)$ \\
Medications & $1(1.05)$ \\
Antidepressants & $23(24.2)$ \\
Pain medications & $64(67.4)$ \\
Iron & $77(81.05)$ \\
Folic acid & $18(18.9)$ \\
\hline &
\end{tabular}

pregnancy. Water was consumed on a daily basis. Milk, juice, and caffeine were consumed 1-3 times per week by $10 \%$ to $37 \%$ during pregnancy. Around $77 \%$ of OTC medications were consumed 1-3 times per month, while prescribed medications were consumed on a daily basis by $74 \%$ of respondents.

No significant correlations were found for consumption habits with age. Table 3 examine the association between consumption habits and demographic variables. Caffeine consumption was the only outcome that showed statistical significance with trimesters $(\mathrm{P}$-value $=0.01$ ). Fish consumption was statistically significant with the education level $(\mathrm{P}$-value $=0.002)$. women with collage degree or above were less consume fish than women with some school education level. According to the monthly income variable, canned food and milk consumption were statistically significant with P-value of 0.03 and 0.048 , respectively. Women with lower income were consumed more canned food and less milk than women with higher income. 
Table 2 Frequency of consumption habits among pregnant women

\begin{tabular}{|c|c|c|c|c|c|}
\hline Substance consumed & 1-3/entire pregnancy $N(\%)$ & 1-3/month N (\%) & 1-3/week N (\%) & 4-6/week N (\%) & 7+/week N (\%) \\
\hline \multicolumn{6}{|l|}{ Food } \\
\hline Meat & $7(7.3)$ & $10(10.4)$ & 38 (39.6) & $23(24)$ & $18(18.8)$ \\
\hline Fish & $9(10.5)$ & $15(17.4)$ & $43(50)$ & $10(11.6)$ & $9(10.5)$ \\
\hline Fruit & $6(6.7)$ & $10(11.1)$ & $31(34.4)$ & $19(21.1)$ & $24(26.7)$ \\
\hline Canned food & $9(12.7)$ & $31(43.7)$ & $22(31)$ & $4(5.6)$ & $5(7)$ \\
\hline Sugary desserts & $1(1.1)$ & $6(6.7)$ & $30(33.3)$ & $24(26.7)$ & $29(32.2)$ \\
\hline Fast food & $7(8.6)$ & $23(28.4)$ & $36(44.4)$ & $9(11.1)$ & $6(7.4)$ \\
\hline \multicolumn{6}{|l|}{ Beverage } \\
\hline Water & 0 & 0 & 0 & $4(4)$ & $96(96)$ \\
\hline Milk & $4(4.9)$ & $12(14.8)$ & $26(32.1)$ & $15(18.5)$ & $24(29.6)$ \\
\hline Juice & $3(3.3)$ & $14(15.2)$ & $9(9.8)$ & $23(25)$ & $43(46.7)$ \\
\hline Caffeine & $2(2.7)$ & $6(8)$ & $28(37.3)$ & $15(20)$ & $24(32)$ \\
\hline \multicolumn{6}{|l|}{ Medication } \\
\hline Over-the-counter & $8(47.1)$ & $5(29.4)$ & 0 & $3(17.6)$ & $1(5.9)$ \\
\hline Prescribed & $3(3.2)$ & $6(6.3)$ & $6(6.3)$ & $10(10.5)$ & $70(73.7)$ \\
\hline
\end{tabular}

\section{Discussion}

The aim of our study was to describe the consumption habits of pregnant women in the Jazan region. The mean age of the respondents was similar to that in a study conducted in Saudi Arabia: 27.8 years [13].

Meat consumption during pregnancy in our sample was $97 \%$, with $82 \%$ of the respondents consuming meat at least once per week. These results were consistent with a study conducted in the USA. On the other hand, studies conducted in Ghana and Nigeria showed that only $33 \%$ and $48 \%$ of pregnant women, respectively, consumed meat at least once per week $[15,16]$. This could be due to the economic differences in the populations. $86 \%$ of pregnant women reported fish consumption, with half reporting 1-3 time per week, Fish consumption habits were higher than those found in the USA study and lower than those in the Ghana study $[6,15]$. This could be due to differences in cultural food habits or the geographical position of Jazan as a coastal region. Fruits were consumed by $90 \%$ of the respondents, with $94 \%$ consuming 1-3 time per week. High fruit consumption in our sample was consistent with the USA and Nigeria studies and higher than the Ghana study $[6,15,16]$. Although canned food contains toxic chemicals, such as Bisphenol A, which impacts mother and child health [8], Canned foods were consumed by $71 \%$ of pregnant women, with $43 \%$ of them consuming them 1-3 times per week or more, a finding similar to the USA study [6]. Sugary desserts and fast food were highly consumed (by $90 \%$ and $81 \%$ of respondents, respectively). Frequency of consumption of these foods was high, with $92 \%$ of respondents consuming dessert at least once a week, while fast food was consumed by $63 \%$ once a week. The USA study reported high consumption habits for sugary desserts and fast food but with much lower frequency than our results [6]. Maternal consumption of fast food is associated with high infant birth weight and increased asthmatic symptoms in children $[17,18]$. Sugary desserts can lead to gestational diabetes and may increase the risk of ovarian cancer $[6,19]$.

Tap water consumption in our sample was $10 \%$. The fact that tap water is more prone to contamination supports the idea that public water can increase the risk of preterm birth, spontaneous abortion, and low birth weight [20]. Milk and juices were highly consumed by pregnant women in our sample. Milk consumption during pregnancy can increase gestational, placental, fetal, and birth weight [21]. However, milk is a rich source of nutrients especially calcium [5]. Fresh fruits and juices that contained folic acid, such as orange and orange juice, are recommended to be consumed by pregnant women [22]. Caffeine was consumed by $75 \%$ of respondents, with $90 \%$ of them consuming caffeine at least once per week. There are inconclusive results about the acceptable level of caffeine intake by pregnant women, but recommendations propose that caffeine intake be reduced during pregnancy [23].

Over-the-counter medication use was low among pregnant women. These results was consistent with study conducted in Riyadh [14]. In contrast, another study conducted in Riyadh tertiary care hospital showed high use of OTC during pregnancy [24]. Moreover, important medical supplements use was sup-optimal for folic acid, iron, and calcium were the most consumed supplements, consumed by $77 \%, 64 \%$, and $58 \%$ of the pregnant women, respectively. Folic acid use among pregnant women in Sudan was $92 \%$, while in the USA it was $77 \%[25,26]$. In 
Table 3 Association of the consumption habits with demographic variables

\begin{tabular}{|c|c|c|c|c|c|c|c|}
\hline \multirow{2}{*}{$\begin{array}{l}\text { Substance } \\
\text { consumed } n=100\end{array}$} & \multicolumn{3}{|l|}{ Trimester } & \multicolumn{2}{|l|}{ Education } & \multicolumn{2}{|l|}{ Income } \\
\hline & 1st N (\%) & 2nd N (\%) & $3 r d ~ N(\%)$ & Some school N (\%) & $\begin{array}{l}\text { Collage } \\
\text { and above } \mathrm{N}(\%)\end{array}$ & $\leq 6000 \mathrm{~N}(\%)$ & $>6000 \mathrm{~N}(\%)$ \\
\hline \multicolumn{8}{|l|}{ Food } \\
\hline \multicolumn{8}{|l|}{ Any meat } \\
\hline Yes & $17(94.4)$ & 39 (97.5) & 41 (97.6) & 43 (95.6) & $54(98.2)$ & 47 (97.9) & $50(96.2)$ \\
\hline No & $1(5.6)$ & $1(2.5)$ & $1(2.4)$ & $2(4.4)$ & $1(1.8)$ & $1(2.1)$ & $2(3.8)$ \\
\hline P-value & $0.58^{\mathrm{a}}$ & & & $0.58^{\mathrm{a}}$ & & 0.99 & \\
\hline \multicolumn{8}{|l|}{ Any fish } \\
\hline Yes & $14(77.8)$ & $36(90)$ & $36(85.7)$ & 44 (97.8) & $42(76.4)$ & 43 (89.6) & $43(82.4)$ \\
\hline No & $4(22.2)$ & $4(10)$ & $6(14.3)$ & $1(2.2)$ & $13(23.6)$ & $5(10.4)$ & $9(17.6)$ \\
\hline P-value & 0.46 & & & $0.002^{*}$ & & 0.32 & \\
\hline \multicolumn{8}{|l|}{ Fresh fruit } \\
\hline Yes & $16(88.9)$ & $37(92.5)$ & $37(88.1)$ & $41(91.1)$ & $49(89.1)$ & $41(85.4)$ & $49(94.2)$ \\
\hline No & $2(11.1)$ & $3(7.5)$ & $5(11.9)$ & $4(8.9)$ & $6(10.9)$ & $7(14.6)$ & $3(5.8)$ \\
\hline P-value & $0.75^{\mathrm{a}}$ & & & $0.99^{\mathrm{a}}$ & & $0.18^{\mathrm{a}}$ & \\
\hline \multicolumn{8}{|l|}{ Any canned foods } \\
\hline Yes & $11(61.1)$ & $29(72.5)$ & 31.(73.8) & $30(66.7)$ & $41(74.5)$ & $39(81.3)$ & $32(61.5)$ \\
\hline No & $7(38.9)$ & $11(27.5)$ & $11(26.2)$ & $15(33.3)$ & $14(25.5)$ & $9(18.7)$ & $20(38.5)$ \\
\hline P-value & 0.58 & & & 0.38 & & $0.03^{*}$ & \\
\hline \multicolumn{8}{|l|}{ Sugary desserts } \\
\hline Yes & $14(77.8)$ & $36(90)$ & $40(95.2)$ & 41 (91.9) & $49(89.1)$ & 45 (93.8) & 45 (86.5) \\
\hline No & $4(22.2)$ & $4(10)$ & $2(4.8)$ & $4(8.1)$ & $6(10.9)$ & $3(6.2)$ & $7(13.5)$ \\
\hline P-value & $0.11^{\mathrm{a}}$ & & & $0.99^{\mathrm{a}}$ & & $0.32^{\mathrm{a}}$ & \\
\hline \multicolumn{8}{|l|}{ Fast foods } \\
\hline Yes & $14(77.8)$ & $31(77.5)$ & $36(85.7)$ & $37(82.2)$ & $44(80)$ & $39(81.3)$ & $42(80.8)$ \\
\hline No & $4(22.2)$ & $9(22.5)$ & $6(14.3)$ & $8(17.8)$ & $11(20)$ & $9(18.7)$ & $10(19.2)$ \\
\hline P-value & 0.59 & & & 0.77 & & 0.95 & \\
\hline \multicolumn{8}{|l|}{ Beverage } \\
\hline \multicolumn{8}{|l|}{ Any milk } \\
\hline Yes & $13(72.2)$ & $31(77.5)$ & $37(88.1)$ & $36(80)$ & 45 (81.8) & $35(72.9)$ & 46 (88.5) \\
\hline No & $5(27.8)$ & $9(22.5)$ & $5(11.9)$ & $9(20)$ & $10(18.2)$ & $13(27.1)$ & $6(11.5)$ \\
\hline P-value & 0.27 & & & 0.81 & & $0.048^{*}$ & \\
\hline \multicolumn{8}{|l|}{ Any juice } \\
\hline Yes & $16(88.9)$ & $37(92.5)$ & 39 (92.9) & $41(91.1)$ & $51(92.7)$ & $43(89.6)$ & $49(94.2)$ \\
\hline No & $2(11.1)$ & $3(7.5)$ & $3(7.1)$ & $4(8.9)$ & $4(7.3)$ & $5(11.4)$ & $3(5.8)$ \\
\hline P-value & $0.79^{\mathrm{a}}$ & & & $0.99^{\mathrm{a}}$ & & $0.47^{\mathrm{a}}$ & \\
\hline \multicolumn{8}{|l|}{ Caffeine } \\
\hline Yes & $10(55.6)$ & $36(90)$ & $29(69)$ & $37(82.2)$ & $38(69.1)$ & $36(75)$ & $39(75)$ \\
\hline No & $8(44.4)$ & $4(10)$ & $13(31)$ & $8(17.8)$ & 17 (30.9) & $12(25)$ & $13(25)$ \\
\hline P-value & $0.01^{*}$ & & & 0.13 & & 1 & \\
\hline \multicolumn{8}{|l|}{ Medication } \\
\hline \multicolumn{8}{|l|}{ OTC medication } \\
\hline Yes & $3(16.7)$ & $5(12.5)$ & $9(21.4)$ & $10(22.2)$ & $7(12.7)$ & $9(18.8)$ & $8(15.4)$ \\
\hline No & 15 (83.3) & $35(87.5)$ & $33(78.6)$ & $35(77.8)$ & $48(87.3)$ & $39(81.2)$ & $44(84.6)$ \\
\hline P-value & 0.56 & & & 0.20 & & 0.65 & \\
\hline \multicolumn{8}{|c|}{ Prescribed medication } \\
\hline Yes & $18(100)$ & $38(95)$ & 39 (92.9) & $42(93.3)$ & $53(96.4)$ & 45 (93.8) & $50(96.2)$ \\
\hline No & $0(0)$ & $2(5)$ & $3(7.1)$ & $3(6.7)$ & $2(3.6)$ & $3(6.2)$ & $2(3.8)$ \\
\hline P-value & $0.83^{\mathrm{a}}$ & & & $0.65^{\mathrm{a}}$ & & $0.66^{a}$ & \\
\hline
\end{tabular}

* Statistically significant

a Based-on Fisher exact test 
Saudi Arabia, study conducted in Riyadh showed a high use of dietary supplements with $96 \%$ for folic acid, iron $89 \%$ and calcium $82 \%$ [27].

Our results showed a significant positive increase in the caffeine consumption by trimesters. These results were consistent with previous finding [28]. In contrast, some studies showed no difference in caffeine consumption regard trimesters or negative association [6, 29]. These differences could be due to differences in the measurement of caffeine. Moreover, our study revealed lower consumption of fish by women with higher education level than women with lower education level. On the other hand, studies showed positive increase of fish consumption with education level [30,31]. These differences could be due small sample size in our study. Furthermore, women with lower income consume more canned food than women with higher income. This result was reported by USA study [6]. Milk consumption was higher among high income women than low income women. In contrast, there was no significant association between milk consumption and level of income among pregnant women in the USA study [6].

In conclusion, this study summaries the consumption habits of Saudi women, revealing high consumption habits of food and beverages among pregnant women. In contrast, lower use of OTC and prescribed medication with sup-optimal intake of folic acid, iron, calcium, and vitamins during pregnancy. Moreover, there was a positive association between caffeine intake and trimesters. Furthermore, there was negative association between education level and fish intake. Finally, canned foods consumption was higher among low income pregnant women.

\section{Limitations}

This study describes the consumption habits of pregnant women in the Jazan region. One of limitations of the study is self-reported quality, which can increase reporting bias. Moreover, the small sample size due to low prenatal care follow-up can lead to sampling bias. In addition, the questionnaire is not for complete diary assessment.

\section{Abbreviations}

OTC: over-the counter; PHC: primary health care; FBMIQ: Food, Beverage, and Medication Intake Questionnaire; SR: Saudi Riyal.

\section{Authors' contributions \\ $A A D, R M S, M Y A, Z Y S, M M J$, and KAM conceptualized and designed the study, conducted data collection, and wrote the report. TA supervised the work, car- ried out the initial analysis, drafted, reviewed, and revised the manuscript, and approved the final manuscript as submitted. All authors read and approved the final manuscript.}

\section{Author details}

${ }^{1}$ Department of Family and Community Medicine, Faculty of Medicine, Jazan University, Jazan, Kingdom of Saudi Arabia. ${ }^{2}$ Faculty of Medicine, Jazan University, Jazan, Kingdom of Saudi Arabia.
Acknowledgements

We would like to thank the collaborating primary health care centers and all Pregnant women who participated in the study.

\section{Competing interests}

The authors declare that they have no competing interests.

\section{Availability of data and materials}

The data are available from the corresponding author on reasonable request.

\section{Consent for publication}

Not applicable as the manuscript does not contain any data from any individual person

\section{Ethics approval and consent to participate}

Ethical approval was obtained from the Jazan Diabetic Center Institutional Review Board. Written informed consent was obtained from each participant who filled out the self-administered questionnaire and verbal consent was provided for the phone questionnaire. All participants read, understood, and signed a written consent form. Participants' privacy was respected, and data were kept confidentially and used for study purposes only.

\section{Funding}

None.

\section{Publisher's Note}

Springer Nature remains neutral with regard to jurisdictional claims in published maps and institutional affiliations.

Received: 5 October 2018 Accepted: 9 November 2018

Published online: 16 November 2018

\section{References}

1. Picciano MF. Pregnancy and lactation: physiological adjustments, nutritional requirements and the role of dietary supplements. J Nutr. 2003;133:1997S-2002S. https://doi.org/10.1093/jn/133.6.1997S.

2. Kaiser $L$, Allen LH. Position of the American Dietetic Association: nutrition and lifestyle for a healthy pregnancy outcome. J Am Diet Assoc. 2008;108:553-61.

3. Keen CL, Clegg MS, Hanna LA, Lanoue L, Rogers JM, Daston GP, et al. The plausibility of micronutrient deficiencies being a significant contributing factor to the occurrence of pregnancy complications. J Nutr. 2003;133(5 Suppl 2):1597S-605S.

4. Williamson CS. Nutrition in pregnancy. Nutr Bull. 2006;31:28-59.

5. Batcher OM, Nichols JM. Identifying important food sources of nutrients. J Nutr Educ. 1984;16:177-81.

6. Santiago SE, Park GH, Huffman KJ. Consumption habits of pregnant women and implications for developmental biology: a survey of predominantly Hispanic women in California. Nutr J. 2013;12:1-14.

7. Halldorsson TI, Strøm M, Petersen SB, Olsen SF. Intake of artificially sweetened soft drinks and risk of preterm delivery: a prospective cohort study in 59,334 Danish pregnant women. Am J Clin Nutr. 2010;92:626-33.

8. Braun JM, Kalkbrenner AE, Calafat AM, Bernert JT, Ye X, Silva MJ, et al. Variability and predictors of urinary bisphenol a concentrations during pregnancy. Environ Health Perspect. 2011;119:131-7.

9. Lupattelli A, Spigset O, Twigg MJ, Zagorodnikova K, Mårdby AC, Moretti $M E$, et al. Medication use in pregnancy: a cross-sectional, multinational web-based study. BMJ Open. 2014;4:e004365.

10. Mitchell AA, Gilboa SM, Werler MM, Kelley KE, Louik C, Hernández-Díaz S. Medication use during pregnancy, with particular focus on prescription drugs: 1976-2008. Am J Obstet Gynecol. 2011;205:51.e1-8. https://doi. org/10.1016/j.ajog.2011.02.029.

11. Servey J, Chang J. Over-the-counter medications in pregnancy. Am Fam Physician. 2014;90:548-55.

12. Moradi-Lakeh M, El Bcheraoui C, Afshin A, Daoud F, Almazroa MA, A Saeedi $M$, et al. Diet in Saudi Arabia: findings from a nationally representative survey. Public Health Nutr. 2017;20:1075-81. 
13. Almurshed KS, Bani IA, Al-Kanhal MA, Al-Amri MA. A study of maternal dietary intake during pregnancy in Riyadh, Saudi Arabia. J Fam Commun Med. 2007;14:9-13.

14. Zaki NM, Albarraq AA. Use, attitudes and knowledge of medications among pregnant women: a Saudi study. Saudi Pharm J. 2014;22:419-28. https://doi.org/10.1016/j.jsps.2013.09.001.

15. Nti CA, Larweh PM, Gyemfua-Yeboah Y. Food consumption patterns, dietary quality and health status of expectant mothers: Case studies in suburban and rural communities in Ghana. Int J Consum Stud. 2002.

16. Maduforo AN, Nwosu OIC, Ndiokwelu Cl, Obiakor-Okeke PN. Food superstition, feeding practices and nutritional anthropometry of pregnant women. JORIND. 2013;11:12-28.

17. Wen LM, Simpson JM, Rissel C, Baur LA. Maternal "junk food" diet during pregnancy as a predictor of high birthweight: findings from the healthy beginnings trial. Birth. 2013;40:46-51. https://doi.org/10.1111/birt.12028.

18. von Ehrenstein OS, Aralis H, Flores MES, Ritz B. Fast food consumption in pregnancy and subsequent asthma symptoms in young children. Pediatr Allergy Immunol. 2015;26(571):577.

19. King MG, Olson SH, Paddock L, Chandran U, Demissie K, Lu SE, et al. Sugary food and beverage consumption and epithelial ovarian cancer risk: a population-based case-control study. BMC Cancer. 2013;13:94. https:// doi.org/10.1186/1471-2407-13-94.

20. Bove F, Shim Y, Zeitz P. Drinking water contaminants and adverse pregnancy outcomes: a review. Environ Health Perspect. 2002;110(SUPPL. 1):61-74.

21. Melnik BC, John SM, Schmitz G. Milk consumption during pregnancy increases birth weight, A risk factor for the development of diseases of civilization. J Transl Med. 2015;13:1-11.

22. McGuire S. U.S. Department of Agriculture and U.S. Department of Health and Human Services, Dietary Guidelines for Americans, 2010. 7th Edition, Washington, DC: U.S. Government Printing Office, January 2011. Adv Nutr. 2011;2(3):293-4.
23. Loomans EM, Hofland L, van der Stelt $\mathrm{O}$, van der Wal MF, Koot HM, Van den Bergh $\mathrm{BRH}$, et al. Caffeine intake during pregnancy and risk of problem behavior in 5- to 6-year-old children. Pediatrics. 2012;1:peds-2011.

24. Raheel H, Alsakran S, Alghamdi A, Ajarem M, Alsulami S, Mahmood A. Antibiotics and over the counter medication use and its correlates among arab pregnant women visiting a tertiary care hospital in Riyadh, Saudi Arabia. Pakistan J Med Sci. 2017;33:452-6.

25. Abdullahi H, Gasim Gl, Saeed A, Imam AM, Adam I. Antenatal iron and folic acid supplementation use by pregnant women in Khartoum, Sudan. BMC Res Notes. 2014;7:1-4.

26. Branum AM, Bailey R, Singer BJ. Dietary supplement use and folate status during pregnancy in the United States. J Nutr. 2013;143:486-92. https:// doi.org/10.3945/jn.112.169987.

27. Alfawaz HA, Khan N, Aloteabi N, Hussain SD, Al-Daghri NM. Factors associated with dietary supplement use in Saudi pregnant women. Reprod Health. 2017;14:1-6.

28. Boylan SM, Cade JE, Kirk SFL, Greenwood DC, White KLM, Shires S, et al. Assessing caffeine exposure in pregnant women. Br J Nutr. 2008; 100:875-82

29. Grosso LM, Rosenberg KD, Belanger K, Saftlas AF, Leaderer B, Bracken MB. Maternal caffeine intake and intrauterine growth retardation. Epidemiology. 2001;12:447-55

30. Hibbeln JR, Davis JM, Steer C, Emmett P, Rogers I, Williams C, et al. Maternal seafood consumption in pregnancy and neurodevelopmental outcomes in childhood (ALSPAC study): an observational cohort study. Lancet. 2007;369:578-85.

31. Oken E, Radesky JS, Wright RO, Bellinger DC, Amarasiriwardena CJ, Kleinman KP, et al. Maternal fish intake during pregnancy, blood mercury levels, and child cognition at age 3 years in a US cohort. Am J Epidemiol. 2008;167:1171-81.
Ready to submit your research? Choose BMC and benefit from:

- fast, convenient online submission

- thorough peer review by experienced researchers in your field

- rapid publication on acceptance

- support for research data, including large and complex data types

- gold Open Access which fosters wider collaboration and increased citations

- maximum visibility for your research: over 100M website views per year

At BMC, research is always in progress.

Learn more biomedcentral.com/submissions 